\title{
Wages, Hours and Human Capital over the Life Cycle
}

\author{
ROBERT A HART \\ Department of Economics, \\ University of Stirling, \\ Scotland, FK9 4LA \\ Tel: (+44) 1786473792 \\ Fax: (+44) 1786467471 \\ Email: r.a.hart@stir.ac.uk) \\ and \\ YUE MA \\ Department of Economics \\ Lingnan University, \\ Hong Kong, China \\ Tel: (852) 26167202 \\ Fax: (852) 28917940 \\ Email: yuema@Ln.edu.hk
}

\section{August, 2008}

\begin{abstract}
We investigate wage-hours contracts within a four-period rent sharing model that incorporates asymmetric information. Distinctions are made among (a) an investment period, (b) a period in which the parties may separate (quits or layoffs) or continue rent accumulation and sharing, (c) a post investment period and, (d) retirement. We establish that increases in both wage rates and hours of work in the post-investment period serve to minimise sub-optimal separations and, moreover that both wage and hours schedules are concave. Testing is based on 13 waves of British Household Panel Survey from 1991 to 2003.
\end{abstract}

Key Words: Wage-hours Contracts, Asymmetric Information; Four Period Model.

JEL Classification: J41, J33

Acknowledgements: This project was funded by the Nuffield Foundation under the Social Science Small Grants Scheme. We are grateful to a Reviewer for several perceptive comments and to Alessandro Gaj and Elizabeth Roberts for research assistance. 


\section{Introduction}

This paper develops a life cycle wage-hours contract model. It adopts a human capital approach in which the worker and the firm seek to share rent optimally when faced with the problem of asymmetric information. ${ }^{1}$ It is a four-period model, covering initial investment, post-investment, pre-retirement and retirement periods. The contract is specified in relation to wage earnings - i.e. the hourly wage rate multiplied by weekly hours - and not simply the hourly wage rate. The fact the parties bargain over both the wage rate and working hours is well understood in the firm-union bargaining literature (Pencavel, 1991; Trejo, 1993). Far less recognition has been given to the broader role of working time within rent sharing contracts. From a policy perspective, our model allows us to investigate an important, yet under-researched, aspect of working time over the life cycle. Thus, while numerous papers have been devoted to the reasons for and the consequences of retirement decisions, relatively few studies have investigated wagehours decisions as retirement approaches. A notable exception is the paper by Gustman and Steinmeier (1986) who are also interested in hours of work within an optimal labour supply life cycle model.

Human capital returns to acquired work skills and organisational know-how have implications for both extensive and intensive labour margins (Hart and Ma, 2000). The first of these, and the one most researched in the literature, is the length of job tenure. Given rent sharing agreements, higher investments may be expected, ceteris paribus, to induce longer tenure. Preventing losses of positive joint rents through sub-optimal quits

\footnotetext{
${ }^{1}$ Malcomson (1999) provides a review of this class of model, including a comparative evaluation with other rent sharing approaches.
} 
and layoffs is the extensive margin goal of the wage contract. To the extent that investments involve firm-specific skills, then quits and layoffs also influence returns in subsequent jobs. The intensive margin concerns the worker's per-period utilisation, measured in terms of daily or weekly average hours of work. In this case, it is well known that higher investments would be expected, ceteris paribus, to induce longer average hours of work (e.g. Ehrenberg, 1971). The degree of investment amortisation is dependent both on length of tenure and on intensity of work per-period. If the wage rate is set to minimise separations for given hours, the contract solution will not be fully efficient if hours are themselves not optimal.

The four-period approach allows us to move beyond establishing that wages rise with work experience since it discriminates between wage rises in the early and later years of tenure. A particularly important generalisation is that we are able to move away from a simple dichotomy between initial and post-investment periods. In our framework, investment within the firm may be undertaken in periods 1 and 2 . This allows us to produce results about relative investment intensities in the early and later stages of onthe-job experience and, therefore, to investigate the curvature of wage profile over the life cycle. It is shown that hours also rise with work experience and, as with the wage-rate, we are able to evaluate likely hours profiles with respect to early and later years of tenure. We are also concerned with the inter-relatedness of wage and hours decisions. Thus, we investigate relative income effects between wages and working time, again differentiating between early and later years of tenure. This dimension of our work underlines the fact that modelling the intensive margin of the firm's operation would appear to be an essential requirement in the evolution of compensation over the life cycle. We might 
expect, for example, that income effects are significantly different during the preretirement period compared to early years of job tenure.

On the empirical side, we estimate separate wage rate and hours growth equations using individual-level data from the British Household Panel Survey (BHPS), 1991-2003. We simulate the combined wage-hour effects in order to examine decompositions of the related wage/hours/earnings-experience profiles. Further, in the light of theoretical derivations, we differentiate between workers whose last job change occurred a considerable time before the age of retirement and those who changed jobs nearer to retirement. Like the symmetric-information implicit risk-sharing model of Beaudry and DiNardo (1995), our model predicts that hours are influenced by wages through an income effect. Additionally, we predict that hours are determined by work experience. A key empirical finding is that the positive impact of rent sharing on hours more than offsets the negative income effect. Hours rise with experience over the life cycle.

We allow for both specific and general human capital investments.

Conventionally, we treat specific capital as having zero-return in the alternative employment. Period 1 is the investment period when the worker is young. Period 2 then accommodates the possibilities that the worker stays with the firm or moves - through either a quit or a layoff - to an alternative firm. If the worker stays, then the parties share the post-investment return to period 1 investments. They also undertake additional investment, the returns to which are realised in period 3. If the parties separate, then period 2 marks the investment period in the new firm. Period 3 is the post-investment period. Finally, the worker retires at the beginning of period 4. Moving from a three- 
period (e.g. Johnson, 1996) to a four-period modelling perspective adds to modelling complexity, but permits richer insights into the evolutions of wages and hours profiles.

\section{Background framework}

The wage-hour contracts adopt the basic modelling approaches of Hashimoto (1979) and Carmichael (1983). The analysis is conducted in terms of the marginal worker whose initial wage earnings are determined on a perfectly competitive spot market. At the outset, the firm and the worker must 'take' the initial wage-hours combination determined in the market place. Subsequently, training endows the worker with firmspecific skills and so in the second period rent sharing arising from this accrued return allows the parties to deviate from spot earnings thereby producing potentially different wage-hours combinations.

The marginal worker receives contractual wage $w_{i}$ in the $i$-th period. The worker's pre-entry endowment of general human capital is worth $w_{1}$ in the open market and this is not augmented within the firm. Both parties are risk neutral. ${ }^{2}$ The firm provides specific training at a cost, $C\left(M_{i}\right)$, where $M_{i}$ is the (uncertain) amount of human capital in the $i$-th period. Ex ante, each party knows only the distributions of $\eta_{i}$ (the disturbance on the post-training productivity in the $i$-th period) and $\theta_{i}$ (the post-training job satisfaction of the workers in the $i$-th period). The density functions of $\eta_{i}$ and $\theta_{i}$ are $f\left(\eta_{i}\right)$ and $q\left(\theta_{i}\right)$ with $E\left(\theta_{i}\right)=E\left(\eta_{i}\right)=\operatorname{Cov}\left(\eta_{i}, \theta_{i}\right)=0$. Ex post, information cannot be exchanged; separation decisions are made independently.

\footnotetext{
${ }^{2}$ These convenient simplifying assumptions follow earlier related papers (e.g. Carmichael, 1983). Assuming risk aversion on the part of workers does not change our results qualitatively.
} 
General and specific elements of human capital acquired within the firm are treated in much of the existing literature as if it is possible, a priori, to demarcate strictly between them. This is highly unlikely in practice. Especially where jobs involve complex sets of functional and organisational requirements, it would be difficult to assess definitively which parts of skill acquisition and know-how are of potential use in alternative employment and which are not. Accordingly, we assume that the proportion of general human capital is a random variable $\varepsilon$ with a distribution of $v($.$) . If the worker$ leaves the firm at the end of a period, we assume that the outside firm knows whether separation is due to the worker being fired or quitting voluntarily. If the worker is fired, this is regarded as a signal that skills have not been acquired to a satisfactory level. In this event, the worker does not gain any increase of general human capital. If the worker quits, his general human capital will increase by a proportion, with $g=\int_{0}^{1} \varepsilon v(\varepsilon) d \varepsilon$, where $0 \leq g \leq 1$.

The probability of a worker deciding to quit at the end of period $i-1$ is

$$
Q_{i}=Q\left(\theta_{i}^{*}\right)=\int_{-\infty}^{\theta_{i}^{*}} q\left(\theta_{i}\right) d \theta_{i}
$$

while the probability of the firm wanting to fire a worker at the end of period $i-1$ is

$$
F_{i}=F\left(\eta_{i}^{*}\right)=\int_{-\infty}^{\eta_{i}^{*}} f\left(\eta_{i}\right) d \eta_{i}
$$

where $\theta_{i}^{*}$ is the level of job satisfaction that leaves the worker indifferent about leaving and $\eta_{i}{ }^{*}$ is the level of productivity that leaves the firm indifferent over employing the worker. In period $i-1$, specific training $C\left(M_{i}\right)$ is expected to raise hourly productivity in 
the subsequent period by $M_{i}+\eta_{i}$, where $\eta_{i}$ is revealed to the firm at the end period $i-1$. Over the time, the human capital is assumed to appreciate at the rate of $\delta$. The worker's job satisfaction $\theta_{i}$ is revealed to the worker at the end of period $i-1$. Without loss of generality, the discount rate is set to zero. Hours in period $i$ is denoted by $h_{i}$ with the worker's associated disutilities represented by $D\left(h_{i}\right)$. In period $1, h_{1}$ and $w_{1}$ are determined on the open competitive market.

\section{Joint wealth maximisation with a retirement constraint}

The expected joint wealth $V$ is the sum of the wealth over three periods that the worker is in the labour force:

$$
V=V_{1}+V_{2}+V_{3} .
$$

We begin, in sub-sections (a) and (b), by detailing the compositions of the constituent parts of $V$ in (3). Table 1 provides a comprehensive summary of this discussion.

\section{(a) Periods 1 and 2}

A two-period time line of quasi rent is illustrated in Figure 1. Since returns to training investments are not realised until period 2, wealth in period 1 consists of wage earnings net of specific training cost and the disutility of working; thus

$$
V_{1}=w_{1} \cdot h_{1}-C\left(M_{2}\right)-D\left(h_{1}\right) .
$$

Combining periods 1 and 2, the parties' joint wealth consists of the returns arising from three mutually exclusive and exhaustive events, weighted by the probability of their occurrence. The worker may be fired or not-fired at the end of period 1 . In the event of 
the worker not being fired, separation may occur due to a quit decision or the employment relationship may continue. In all three outcomes the first period rent consists of wage compensation net of training cost and work disutility $\left(w_{1} \cdot h-C-D(h)\right)$. If the worker is fired or voluntarily quits, the firm itself cannot obtain second period rent. If the worker remains with the firm, second period rent differs from the first period due enhanced productivity and job satisfaction as well as to the fact that second-period hours may differ from those in the first period.

\section{Figure 1: Time line of quasi-rent}

\section{Period $1 \quad$ Period 2}

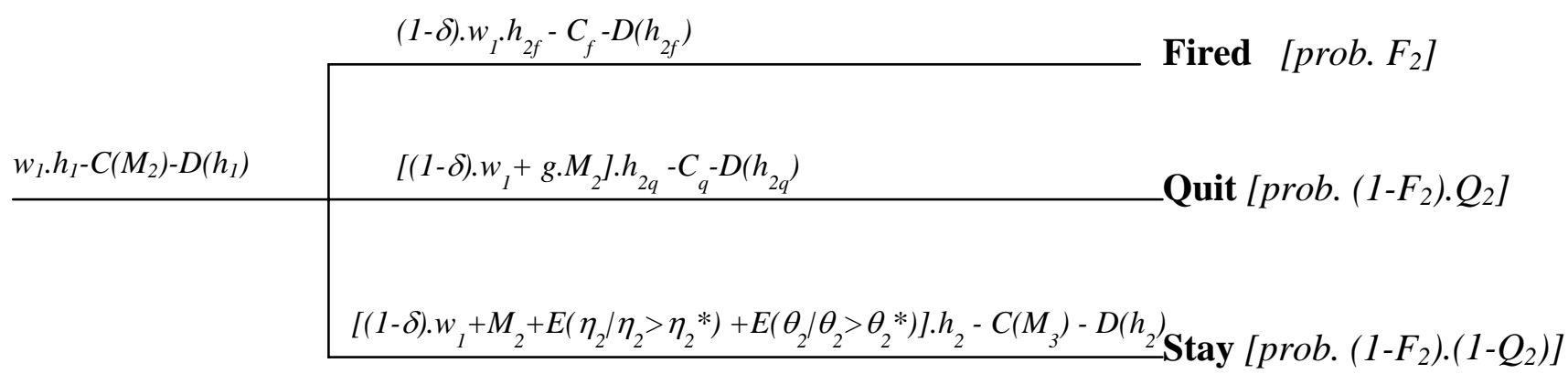

If the worker leaves the firm at the end of period 1, it is either through quitting or being fired. To avoid excessive complexity, we make the assumption that, if either type of separation occurs, the worker will not subsequently rejoin the firm. For subsequent wages, hours and costs, we assign subscripts ' $q$ ' and ' $f$ ' to denote, respectively, quit and firing decisions. We assume that if the worker is fired then this is regarded by potential employers as a signal that skills have not been acquired to a satisfactory level. In this event, he will not receive a higher return based on acquired human capital in firm 1. General human capital, after allowing depreciation, is $(1-\delta) . w_{1}$ with expected working 
hours $h_{2 f}$ The worker will also incur training costs, $C_{f}$ If the worker quits the firm, he will obtain a proportion of human capital, g. $M_{2}$, which is useful for the outside job. His general human capital is $(1-\delta) \cdot w_{1}+g \cdot M_{2}$, expected working hours is $h_{2} q$ and training cost is $C_{q}$. Finally, if he stays in the current firm, he will gain the full amount of the increase of human capital, $M_{2}$.

Taken together, these three possibilities at the end of the initial training period lead to $V_{2}$ being expressed as the sum of returns of three mutually exclusive and exhaustive events: $V_{2}=F_{2} \cdot\left[(1-\delta) \cdot w_{1} \cdot h_{2 f}-C_{f}-D\left(h_{2 f}\right)\right] \quad$ (the worker is fired at the end of period 1)

$+\left(1-F_{2}\right) \cdot Q_{2} \cdot\left\{\left[(1-\delta) \cdot w_{1}+g \cdot M_{2}\right] \cdot h_{2 q}-C_{q}-D\left(h_{2 q}\right)\right\}$ (the worker quits at the end of period 1)

$+\left(1-F_{2}\right) \cdot\left(1-Q_{2}\right) \cdot\left\{\left[(1-\delta) \cdot w_{1}+M_{2}+E\left(\eta_{2} \mid \eta_{2}>\eta_{2}{ }^{*}\right)+E\left(\theta_{2} \mid \theta_{2}>\theta_{2}{ }^{*}\right)\right] \cdot h_{2}-C\left(M_{3}\right)-D\left(h_{2}\right)\right\}$

(the worker stays at the end of period 1)

where $D($.$) is the disutility of working.$

(b) Period 3

In period 3, the pre-retirement period, the worker reaches an age where no further training takes place. The wealth of period $3, V_{3}$, is conditional on whether, at the end of period 1, the worker was either fired $\left(V_{f}\right)$, or quit the firm $\left(V_{q}\right)$ or stayed with the firm $\left(V_{s}\right)$, i.e. $V_{3}=V_{f}+V_{q}+V_{s}$ (see Table 1). Recall that if separation takes place (quit or layoff) then the worker will not return to the firm. We discuss each possibility in turn. 
(i) The worker is fired at the end of period 1

The expected period 3 income from an outside job is given by

$$
V_{f}=F_{2 \cdot}\left[w_{3 f} \cdot h_{3 f f}-D\left(h_{3 f f}\right)\right]
$$

where $\left(w_{3 f}, h_{3 f f}\right)$ is the expected wage-hour contract with $w_{3 f}=w_{1} \cdot(1-\delta)^{2}+M_{3 f}$, where $M_{3 f}$ is the expected increase of human capital stemming from period 2 training.

(ii) The worker quits at the end of period 1

The expected outside job income is given by

$$
V_{q}=\left(1-F_{2}\right) \cdot Q_{2} \cdot\left\{\left[\left(w_{1} \cdot(1-\delta)+g \cdot M_{2}\right) \cdot(1-\delta)+M_{3 q}\right] \cdot h_{3 q q}-D\left(h_{3 q q}\right)\right\}
$$

where $\left[\left(w_{1} \cdot(1-\delta)+g \cdot M_{2}\right) \cdot(1-\delta)+M_{3 q}\right]$ is the expected contract wage, $h_{3 q q}$ is the expected hours of work and $M_{3 q}$ is the expected increase of human capital.

(iii) The worker stays at the end of period 1

In this event, $V_{s}$ is expressed further as the sum of returns of three mutually exclusive and exhaustive events similar to $V_{2}$ (see Table 1 )

$$
\left.V_{S}=\left(1-F_{2}\right) \cdot\left(1-Q_{2}\right) \cdot F_{3} \cdot\left[(1-\delta) \cdot w_{1} \cdot+g \cdot M_{2}\right) \cdot(1-\delta) \cdot h_{3 f}-D\left(h_{3 f}\right)\right]
$$

(the worker is fired at the end of period 2)

$$
+\left(1-F_{2}\right) \cdot\left(1-Q_{2}\right) \cdot\left(1-F_{3}\right) \cdot Q_{3} \cdot\left\{\left[\left(w_{1} \cdot(1-\delta)+g \cdot M_{2}\right) \cdot(1-\delta)+g \cdot M_{3}\right] \cdot h_{3 q^{-}} D\left(h_{3 q}\right)\right\}
$$

(the worker quits at the end of period 2) 
$+\left(1-F_{2}\right) \cdot\left(1-Q_{2}\right) \cdot\left(1-F_{3}\right) \cdot\left(1-Q_{3}\right) \cdot\left\{\left[\left(w_{1} \cdot(1-\delta)+M_{2}\right) \cdot(1-\delta)+M_{3}+E\left(\eta_{3} \mid \eta_{3}>\eta_{3} *\right)\right.\right.$
$\left.\left.+E\left(\theta_{3} \mid \theta_{3}>\theta_{3} *\right)\right] \cdot h_{3}-D\left(h_{3}\right)\right\} \quad$ (the worker stays at the end of period 2)

where $h_{3 f}$ and $h_{3 q}$ are the expected hours outside the firm if the worker is fired or quits, respectively.

\section{(c) Model solutions}

We deal first with periods 1 and 2. From the first-order conditions to the problem of maximising wealth in (5) - derived in Theory Appendix (a) - we obtain

$$
w_{2}=(1-\delta) \cdot w_{1}+M_{2}+E\left(\eta_{2} \mid \eta_{2}>\eta_{2}{ }^{*}\right)>w_{1}
$$

and

$$
\begin{gathered}
\alpha-Q_{2} \cdot\left[\beta+\gamma \cdot g \cdot M_{2}\right]-\left(1-Q_{2}\right) \cdot\left[h_{2} \cdot E\left(\theta_{2} \mid \theta_{2}>\theta_{2}{ }^{*}\right)-C\left(M_{3}\right)-D\left(h_{2}\right)\right. \\
\left.+\left[\tau+g \cdot M_{2} \cdot(1-\delta) \cdot h_{3 f}\right]+w_{2} \cdot h_{2}\right]=0 .
\end{gathered}
$$

Derivations of (9) and (10) are given in Results Appendix (b).

Expression (9) provides the well known outcome, illustrated in Figure 2 (a), that the contractual wage rate rises with tenure, or $w_{2}{ }^{*}>w_{1}$. Similar to the proof in Hart and Ma (2000), we can also show that working hours allocated in the post-investment period, conditional on satisfying a marginal disutility constraint, also rise relative to period 1 hours, or $h_{2} *>h_{1}$. Thus, we have the hours profile illustrated in Figure 2 (b). An optimal solution to the problem of maximising wealth in (8) cannot be attained through the choice of a single hourly wage rate, however. The problem is that the parties 
Table 1 Expected life-time wealth

\begin{tabular}{|c|c|c|c|c|c|}
\hline Period $1\left(V_{1}\right)$ & \multicolumn{2}{|l|}{ Period $2\left(V_{2}\right)$} & \multicolumn{2}{|l|}{ Period $3 \quad\left(V_{3}=V_{f}+V_{q}+V_{s}\right)$} & Period 4 \\
\hline \multirow{8}{*}{$\begin{array}{l}\text { Probability }=1.0 \\
w_{1} \cdot h_{1}-C\left(M_{2}\right)- \\
D\left(h_{1}\right)\end{array}$} & $\begin{array}{l}\text { Fired: probability }=F_{2} \\
(1-\delta) \cdot w_{1} \cdot h_{2 f}-C_{f}-D\left(h_{2 f}\right)\end{array}$ & \multirow{7}{*}{$\mathbf{V}_{2}$} & $\begin{array}{l}\text { Probability }=F_{2} \\
w_{3 f} \cdot h_{3 f f}-D\left(h_{3 f f}\right)\end{array}$ & $V_{f}$ & Retirement \\
\hline & Q Quits: probability $=\left(1-F_{2}\right) \cdot Q_{2}$ & & Probability $=\left(1-F_{2}\right) \cdot Q_{2}$ & $V_{q}$ & \\
\hline & $\begin{array}{l}{\left[(1-\delta) \cdot w_{1}+g \cdot M_{2}\right] \cdot h_{2 q^{-}}} \\
C_{q^{-} D\left(h_{2 q}\right)}\end{array}$ & & {$\left[\left(w_{1} \cdot(1-\delta)+g \cdot M_{2}\right) \cdot(1-\delta)+M_{3 q}\right] \cdot h_{3 q q}-D\left(h_{3 q q}\right)$} & & \\
\hline & $\begin{array}{l}\text { Stays: probability }= \\
\left(1-F_{2}\right) \cdot\left(1-Q_{2}\right)\end{array}$ & & $\begin{array}{l}\text { Fired: } \text { probability }=\left(1-F_{2}\right) \cdot\left(1-Q_{2}\right) \cdot F_{3} \\
{\left[w_{1} \cdot(1-\delta)+g \cdot M_{2}\right] \cdot(1-\delta) \cdot h_{3 f}-D\left(h_{3 f}\right)}\end{array}$ & \multirow[t]{4}{*}{$V_{S}$} & \\
\hline & {$\left[(1-\delta) \cdot w_{1}+M_{2}+E\left(\eta_{2} \mid \eta_{2}>\eta_{2} *\right)\right.$} & & Quits: probability $=\left(1-F_{2}\right) \cdot\left(1-Q_{2}\right) \cdot\left(1-F_{3}\right) \cdot Q_{3}$ & & \\
\hline & $\begin{array}{l}\left.+E\left(\theta_{2} \mid \theta_{2}>\theta_{2}^{*}\right)\right] \cdot h_{2}-C\left(M_{3}\right)- \\
D\left(h_{2}\right)\end{array}$ & & {$\left[\left(w_{1} \cdot(1-\delta)+g \cdot M_{2}\right) \cdot(1-\delta)+g \cdot M_{3}\right] \cdot h_{3 q^{-}} D\left(h_{3 q}\right)$} & & \\
\hline & & & Stays: probability $=\left(1-F_{2}\right) \cdot\left(1-Q_{2}\right) \cdot\left(1-F_{3}\right) \cdot\left(1-Q_{3}\right)$ & & \\
\hline & & & $\begin{array}{l}{\left[\left(w_{1} \cdot(1-\delta)+M_{2}\right) \cdot(1-\delta)+M_{3}+\right.} \\
\left.E\left(\eta_{3} \mid \eta_{3}>\eta_{3}{ }^{*}\right)+E\left(\theta_{3} \mid \theta_{3}>\theta_{3} *\right)\right] \cdot h_{3} \\
-D\left(h_{3}\right)\end{array}$ & & \\
\hline
\end{tabular}


are seeking to minimise sub-optimal quits and layoffs, with an eye towards the outside wage, as well as achieving the optimal length of working hours. Intuitively, at least two instruments are required in order to achieve these mutually supportive objectives. Hart and Ma (2000) establish that if an “overtime” premium is paid then contract efficiency is established. This does not rule out the use of other instruments, such as bonus payments (Hashimoto, 1979) or fixed seniority promotion rules (Carmichael, 1983).

Figure 2: Wage and hours profiles

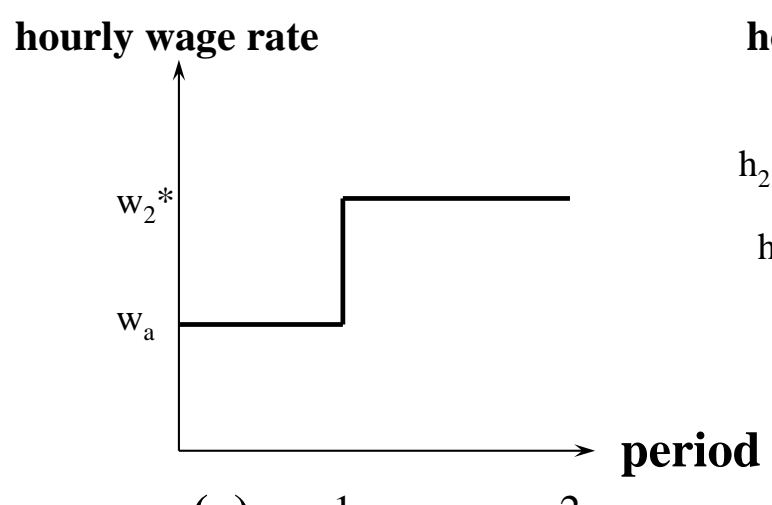

(a) 12

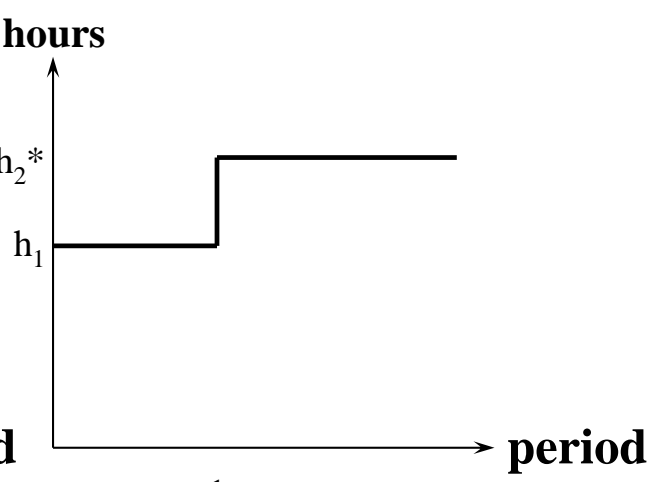

(b) 1

We now deal with period 3. A summary of the expected lifetime wealth, together with the first-order conditions (f.o.c's) for wealth maximisation are set out in the Results Appendix (a). From the f.o.c's (A3) to (A6), it is easily established that workers will quit whenever satisfaction is below $\theta_{i}{ }^{*}$; that is,

$$
\theta_{2}<\theta_{2} *=\left[\beta+\gamma \cdot g \cdot M_{2}\right] / h_{2}-\left[A / h_{2}+E\left(\eta_{2} \mid \eta_{2}>\eta_{2} *\right)\right]
$$

and

$$
\left.\theta_{3}<\theta_{3} *=\left[\mu+g \cdot M_{2} \cdot(1-\delta) \cdot h_{3 q}+g \cdot M_{3} \cdot h_{3 q}\right] / h_{3}-\left[B / h_{3}+E \eta_{3} \mid \eta_{3}>\eta_{3} *\right)\right] .
$$

Further, the firm will fire the workers whenever productivity is below $\eta_{i}{ }^{*}$; that is 


$$
\eta_{2}<\eta_{2} *=\left\{\alpha-Q_{2} \cdot\left[\beta+\gamma \cdot g \cdot M_{2}\right]\right\} /\left[h_{2} \cdot\left(1-Q_{2}\right)\right]-\left[A / h_{2}+E\left(\theta_{2} \mid \theta_{2}>\theta_{2} *\right)\right]
$$

and

$$
\begin{aligned}
& \eta_{3}<\eta_{3}^{*}=\left\{\left[\tau+g \cdot M_{2} \cdot(1-\delta) \cdot h_{3 f}\right]-Q_{3} \cdot\left[\mu+g \cdot M_{2} \cdot(1-\delta) \cdot h_{3 q}+g \cdot M_{3} \cdot h_{3 q}\right]\right\} /
\end{aligned}
$$

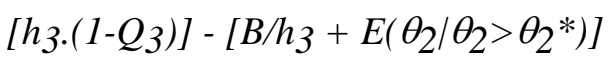

These results state that the party wishing to separate must be made to internalise the entire expected losses from the separation at each period over the working life.

Next we show that it is possible to formulate a wage-hour contract in terms of the parameters of $\eta_{i}^{*}$ and $\theta_{i}^{*}$ to satisfy the first-order conditions (A3) to (A6). For period 3, there exists a wage-hour contract which can minimise the sub-optimal separation of the two parties, with $\left(w_{3} *, h_{3}{ }^{*}\right)$, satisfying the following two equations:

$$
w_{3}=(1-\delta)^{2} \cdot w_{1}+M_{2} \cdot(1-\delta)+M_{3}+E\left(\eta_{3} \mid \eta_{3}>\eta_{3} *\right)
$$

and

$$
\begin{aligned}
{\left[\tau+g \cdot M_{2} \cdot(1-\delta) \cdot h_{3 f}\right]-Q_{3} \cdot\left[\mu+g \cdot M_{2} \cdot(1-\delta) \cdot h_{3 q}+g \cdot M_{3} \cdot h_{3 q}\right] } \\
-\left(1-Q_{3}\right) \cdot\left[h_{3} \cdot E\left(\theta_{3} \mid \theta_{3}>\theta_{3} *\right)-D\left(h_{3}\right)+w_{3} \cdot h_{3}\right]=0
\end{aligned}
$$

Equations (15) and (16) are derived in Theory Appendix (c).

\section{Life cycle changes in investments, wages and hours}

The optimal wage-hour contract $\left(w_{2}{ }^{*}, h_{2}{ }^{*}, w_{3}{ }^{*}, h_{3}{ }^{*}\right)$ the level of human capital investments $\left(M_{2}{ }^{*}, M_{3} *\right)$ are obtained by solving equations (9), (10), (15), (16), (A7) and (A8) simultaneously. In this section, we investigate four sets of questions that arise from these solutions. What are the implications of our model for (a) the level of human capital investment over the life cycle; 
(b) the level of hours over the life cycle;

(c) the income effect on hours in the post-investment period compared to the previous period;

(d) the effects on wages and hours life-time schedules of separation before period 3 ? We deal with each issue in turn.

\section{(a) Human capital investments}

We might expect that, given the retirement constraint, the optimal level of human capital produced by the training investments will rise initially and then fall as the worker becomes older. In effect, for given investments, the age of retirement serves to shorten the potential length of amortisation of period 2 compared to period 1 investments. We show formally in the Theory Appendix (d) that such an outcome is predicted by the model. Providing quit and layoff probabilities as well as the depreciation rate are small, we obtain the outcome

$$
M_{2}>M_{3}>0
$$

that is, returns to human capital investments that are realised in period 3 are less than those realised in period 2. Ceteris paribus, our results suggest that wages and hours rise with experience due to rent sharing and, moreover, the two profiles are concave. In terms of the wage rate, the analysis provides a theoretical underpinning of the slope and shape of the Mincer-equation (Mincer, 1974).

\section{(b) Hours}

There are four explicit conditions and one implicit condition to guarantee that $h_{3}$ rises above $h_{2}$ (see Hart and Ma, 2000):

(i) outside working hours are not far away from $h_{3}$;

(ii) the quit probability $Q_{3}$ is not too high; 
(iii) the marginal disutility of work $D^{\prime}\left(h_{3}\right)$ is not too large;

(iv) $\quad D(0)=0, D^{\prime}(\cdot)>0$ and $\mathrm{D}^{\prime \prime}(\cdot)>0$;

(v) $\quad w_{3}>w_{2}$.

Conditions (ii) and (iv) may well hold in period 3 as the worker is approaching

retirement. However, (i) and (iii) may not hold. This implies hours may fall in the pre-retirement period, independent of the wage. Furthermore, condition (v) may not hold in period 3 either. ${ }^{3}$ This again implies that the hours may fall in period 3.

(c) Income effects on hours

In order to gain a deeper insight into period 3 relative to period 2 hours, we need to consider the income effect on hours. From equation (10) we have

$$
\operatorname{dog}\left(h_{2}\right) / \operatorname{dog}\left(w_{2}\right)=-w_{2} /\left[w_{2}+E\left(\theta_{2} / \theta_{2}>\theta_{2}{ }^{*}\right)-D^{\prime}\left(h_{2}\right)\right]
$$

While by equation (16) we have

$$
\operatorname{dog}\left(h_{3}\right) / \operatorname{dog}\left(w_{3}\right)=-w_{3} /\left[w_{3}+E\left(\theta_{3} / \theta_{3}>\theta_{3}{ }^{*}\right)-D^{\prime}\left(h_{3}\right)\right]
$$

Comparing (18) and (19), we can find that the following three factors increase the income effect of period 3, relative to that of period 2. These are:

$$
w_{3}<w_{2}
$$

\footnotetext{
${ }^{3}$ What can we say about the expected value of $\mathrm{w}_{3}$ relative to $w_{2}$ ? Consider equation (15). It is clear that there are two influences on the value of $w_{3}$ that serve to render the outcome relative to $w_{2}$ as an open empirical question. From (15), if there were no human capital investment in period 2, with the result that $M_{3}=0$, then we would unequivocally obtain $w_{3}<w_{2}$ due to the effect of the investment depreciation term, $\delta$. But $M_{3}>0$ does not ensure the reverse wage inequality because we have established in (17) that human capital investment $M_{3}$ will be less than $M_{2}$. In other words, it would remain the case that $w_{3}<w_{2}$ if the investment $M_{3}$ falls steeply enough so as not to offset the human capital depreciation. Therefore, relative sizes of $w_{3}$ and $w_{2}$ cannot be determined a priori.
} 
(ii) $\theta_{3}<\theta_{2}$, i.e. job satisfaction may be lower when a worker gets older;

(iii) $\quad D^{\prime}\left(h_{3}\right)<D^{\prime}\left(h_{2}\right)$ if $h_{3}<h_{2}$.

\section{(d) Separation before period 3}

Suppose that we distinguish between two groups of workers. The first group consists of individuals who changed their last job relatively late in their working lifetime and who will have short expected tenure (SET). The second group's last job change is at an age that still leaves relatively long expected tenure (LET). ${ }^{4}$ The wage profiles of these two groups are likely to differ. Consider first the implication for human capital investment in (a). We would expect in (17) that $M_{3}$ will fall relative to $M_{2}$ for the SET group considerably more than the LET group as approaching retirement will preclude significant period 2 investments. In relation to wage outcomes in (b), therefore, we would conclude that there is a far greater chance that $w_{3}<w_{2}$ for the SET group compared to the LET group.

The hours profiles may also contrast between the two groups but in this case the picture is more complicated. Suppose, for example, that the conditions listed under the hours effect in (c) and under the income effect in (d) are small except for $w_{3}$ $<w_{2}$. This latter result would serve to depress hours but this would be counteracted by the income effect.

In the empirical estimation reported in Section 6, we examine the consequences of distinguishing between SET and LET groups.

\footnotetext{
${ }^{4}$ In a theoretical and empirical analysis in which human capital investments play a key part, Hübler (1989) explores the optimal number of job moves over work histories.
} 


\section{Estimation}

(a) Wage and hours estimating equations

We use BHPS data on full-time males observed annually from 1991 to 2003. An advantage of using British data is that the labour market is more or less unregulated as far as working time is concerned. The lengths of standard and total weekly hours are generally not subject to statutory interference. ${ }^{5}$ Variable definitions are given in the Data Appendix.

From equation (9), we predict that the wage rate rises with the acquisition of general and specific human capital. We also predict (see discussion around (17)) that the profile will be concave. We use work experience as a proxy for the combined returns to general and specific investments. For J employed individuals (indexed by $j=1, \ldots, J$ ), we have

$$
\log w_{j t}=x_{j t} a+y_{j t} b+\mu_{j}+e_{j t}
$$

where $w_{j t}$ is the hourly straight-time wage rate ${ }^{6}$ for individual $i$ at time $t, x$ is a vector of the individual's human capital attributes (work experience) and y contains other control variables (marital status, firm-size, industry and year dummies); $a$ and $b$ are vectors of parameters to be estimated; $\mu_{j}$ represents individual fixed effects and $e_{j}$ is a zero-mean random variable reflecting unobserved characteristics that affect the wage offer.

\footnotetext{
${ }^{5}$ Minimum hourly premiums for hours in excess of regular hours are also not subject to legislation. Unfortunately, we have no direct information on premium rates for individuals in the BHPS and so they are not included in the analysis. Instead, we focus our study on straight-time wage rates and total hours equations which, taken jointly, provide lower bound estimates a earnings effects.

${ }^{6}$ Paid-for basic hourly wage rates are not directly provided in the BHPS and they were derived on the following basis. Omitting cross-section subscripts, $w=$ [gross weekly earnings]/\{basic weekly hours + [(overtime hours) $\times 1.25]$. The overtime premium of 1.25 is based on estimates by Hart and Ruffell (1993) for males in British production industries. These authors show that the premium remains unaffected by variations in the length of weekly hours.
} 
From equation (10), we establish that hours also rise with work experience. Longer hours are consistent with greater turnover efficiency in the face of sunk investments. The hours-equivalent equation to (20) is expressed:

$$
\log h_{j t}=z_{j t} c+y_{j t} d+v_{j}+u_{j t}
$$

where $h$ is weekly hours; $z$ represents the work experience and - as dictated by equation (10) - the straight-time wage; y are the same controls as in (20); $c$ and $d$ are vectors of parameters; $v$ represents fixed effects; $u$ is the error term.

Our data set contains both employed and unemployed persons. Given the potential for sample selection bias, we adopt the Heckman (1979) two-step procedure. The probability of being unemployed is estimated in an auxiliary probit regression where the sample of both employed and unemployed is included. The explanatory variables in the probit consisted of the individual's age, marital status and category of child dependency. From the probit, we obtained an estimate of the inverse Mills ratio which is added as an additional variable in the wage and hours specification, (20) and (21).

\section{(b) Simulations}

In order to evaluate the contributions of total experience on the wage rate and hours profiles, as well as on wage earnings (i.e. the wage rate times hours), we carried out a simple simulation exercise. Suppose a worker enters a firm immediately after schooling and remains in the firm, without unemployment spells or other major nonvacation breaks, until the age of retirement. How much would wage rates, weekly hours and wage earnings rise with accumulated years of tenure (= experience)? Based on our estimates of equation (20), let $\hat{a}_{1}$ be the estimated coefficient on the 
experience variable, $E X P$ and $\hat{\alpha}_{2}$ the coefficient on $E X P^{2}$ within the $a$ vector. Then, we can evaluate

$$
\frac{\partial\left(\log w_{j}\right)}{\partial(E X P)}=\hat{a}_{1}+2 \hat{a}_{2} \cdot(E X P)
$$

In the estimated hours equation (21), let $\hat{b}_{1}$ be the estimated coefficient on $E X P, \hat{b}_{2}$ on $E X P^{2}$, and $\hat{b}_{3}$ the coefficient on the wage in the $b$ vector. Then, we have

$$
\frac{\partial\left(\log h_{j}\right)}{\partial(E X P)}=\hat{b}_{1}+2 \hat{b}_{2} \cdot(E X P)+\hat{b}_{3} \cdot\left[\frac{\partial\left(\log w_{j}\right)}{\partial(E X P)}\right] .
$$

Combining these wage rate and hours simulations allows us to evaluate the growth rates of wage earnings that are attributable to work experience. Note, however, that these are lower bound earnings estimates because we are assuming implicitly that all weekly hours are compensated at the straight-time wage rate, $w_{t}$. For many workers, marginal weekly hours are paid at an overtime premium. Our construction assumes that this premium rate is 1 which clearly underestimates the true figure. Elsewhere, we establish theoretically that the overtime premium itself will relate to human capital investments and may serve to reduce sub-optimal separations given sunk investments (Hart and Ma, 2000).

\section{(c) SET and LET dichotomies}

Following the discussion in Section 4 (d), we differentiated between individuals with short expected tenure (SET) and those with long expected tenure (LET). We argued that our theoretical developments would lead us to expect to observe different wage and hours returns to experience for the two groups as well as different income effects. Dividing individuals into SET and LET groups is, of necessity, a somewhat arbitrary process. We adopted a simple heuristic approach. We experimented with job-change ages within middle aged groups (between 40 and 
55) in order to find an 'optimum' dividing age. The optimum age was simply the choice that maximised the estimated differences in experience and hours-wage coefficients between the two groups. It turned out that the age was 44. Accordingly, all those changing job at age 44 and above were treated as the SET group with the remainer the LET group.

Letting $D$ be a dichotomous variable that represents the dividing age, our modified versions of (20) and (21) are given by

$$
\log w_{j t}=x_{j t} a_{1}+D \cdot x_{j t} a_{2}+y_{j t} b+\mu_{j}+e_{j t}
$$

and

$$
\log h_{j t}=z_{j t} c_{1}+D \cdot z_{j t} c_{2}+y_{j t} d+v_{j}+u_{j t}
$$

\section{Results}

The estimates in columns (i) and (iii) of Table 2 establish, in line with our theory, that both wage rates and weekly hours rise with work experience. Moreover, both components of earnings exhibit concave profiles. As in many previous supplyside and wage contract models, we obtain a negative income effect in respect of the straight-time wage. From Table 2 and Figure 3, we find from the simulations - i.e. equations (22) and (23) - that a worker receives 11.6 growth in the hourly wage rate

by the fifth year of experience. By 20 years of experience, such growth reaches 33.5 per cent before declining somewhat over the ensuing 10 years. But hours also rise over the life cycle: in other words, the experience effect is greater than the income effect. After 5 years, hours grow 1.3 per cent due to experience and by year 30 hours growth peaks at 5.0 per cent. Combining the two simulations in order to establish the earnings-experience profile, we find that the wage-rate growth from 11.6 per cent 
after 5 years rises to 13.0 per cent in terms of wage earnings. After 25 years, the respective percentages are 30.5 and 36.8 .

Table 2: Wage and hours fixed effects regressions and simulations (BHPS: 1991-2003)

\begin{tabular}{|c|c|c|c|c|c|}
\hline & \multicolumn{2}{|c|}{ Basic wage $(\ln w)$} & \multicolumn{2}{|c|}{ Hours (ln h) } \\
\hline & & (i) & (ii) & (iii) & (iv) \\
\hline \multicolumn{2}{|l|}{ Experience } & $\begin{array}{c}0.030^{*} \\
(0.005)\end{array}$ & $\begin{array}{l}0.032 * \\
(0.005)\end{array}$ & $\begin{array}{l}0.009^{*} \\
(0.002)\end{array}$ & $\begin{array}{l}0.011^{*} \\
(0.003)\end{array}$ \\
\hline \multicolumn{2}{|c|}{ Experience $^{2} / 100$} & $\begin{array}{l}-0.083^{*} \\
(0.002)\end{array}$ & $\begin{array}{l}-0.087 * \\
(0.003)\end{array}$ & $\begin{array}{c}-0.022^{*} \\
(0.001)\end{array}$ & $\begin{array}{c}-0.026^{*} \\
(0.001)\end{array}$ \\
\hline \multicolumn{2}{|l|}{ Wage } & - & - & $\begin{array}{c}-0.193^{*} \\
(0.001)\end{array}$ & $\begin{array}{l}-0.198^{*} \\
(0.003)\end{array}$ \\
\hline \multicolumn{2}{|l|}{ Mills } & $\begin{array}{c}-0.292 \\
(0.267)\end{array}$ & $\begin{array}{c}-0.285 \\
(0.267)\end{array}$ & $\begin{array}{c}0.007 \\
(0.135)\end{array}$ & $\begin{array}{c}0.012 \\
(0.135)\end{array}$ \\
\hline \multicolumn{2}{|l|}{ D } & & $\begin{array}{c}0.155^{*} \\
(0.058)\end{array}$ & & $\begin{array}{c}-0.012 \\
(0.033)\end{array}$ \\
\hline \multicolumn{2}{|l|}{ D.Experience } & & $\begin{array}{l}-0.015^{*} \\
(0.004)\end{array}$ & & $\begin{array}{l}-0.005^{*} \\
(0.002)\end{array}$ \\
\hline \multicolumn{2}{|c|}{ D.(Experience 2 /100) } & & $\begin{array}{l}0.027^{*} \\
(0.006)\end{array}$ & & $\begin{array}{l}0.009 * \\
(0.003)\end{array}$ \\
\hline \multicolumn{2}{|l|}{ D.Wage } & & - & & $\begin{array}{l}0.021^{*} \\
(0.005)\end{array}$ \\
\hline \multicolumn{2}{|l|}{ Sample size } & \multicolumn{4}{|c|}{31976} \\
\hline \multicolumn{6}{|c|}{$\begin{array}{l}\text { Notes: * denotes statistically significant at } 0.01 \text { level. Brackets below } \\
\text { coefficients contain standard errors. Regressions include dummies for years, 2- } \\
\text { digit industries, firm size (1-24 workers, } 25-49 \text {, and over } 50) \text {, whether living with } \\
\text { partner, number of children (see Data Appendix). The dummy variable } D \text { takes } \\
\text { the value of } 1 \text { for those workers who changed job at age } 44 \text { and older. }\end{array}$} \\
\hline \multicolumn{6}{|c|}{$\begin{array}{l}\text { Percentage growth in wage rates, weekly hours and wage earnings attributable to } \\
\text { work experience }\end{array}$} \\
\hline \multicolumn{3}{|c|}{\begin{tabular}{c|c}
$\begin{array}{c}\text { Experience } \\
\text { (years) }\end{array}$ & Wage rates $\left(\mathrm{w}_{\mathrm{t}}\right)$ \\
\end{tabular}} & \multicolumn{2}{|c|}{ Weekly hours $\left(\mathrm{h}_{\mathrm{t}}\right) \quad$ Wag } & $\operatorname{ings}\left(w_{t} \cdot h_{t}\right)$ \\
\hline 5 & & & 1.3 & & .0 \\
\hline 10 & & & 2.7 & & .7 \\
\hline 15 & & & 3.7 & & .9 \\
\hline 20 & & & 4.9 & & .4 \\
\hline 25 & & & 4.9 & & .8 \\
\hline 30 & & & 5.0 & & .3 \\
\hline $\begin{array}{l}\text { Notes: These } \\
\text { of wages, hou } \\
\text { experience. F }\end{array}$ & ares sl & $\begin{array}{l}v \text { the perce } \\
\text { ngs and th } \\
\text { jides corre }\end{array}$ & $\begin{array}{l}\text { atage differen } \\
\text { ir respective } \\
\text { sponding grap }\end{array}$ & between t & $\begin{array}{l}\text { rent values } \\
\text { to total } \\
\text { rs. }\end{array}$ \\
\hline
\end{tabular}



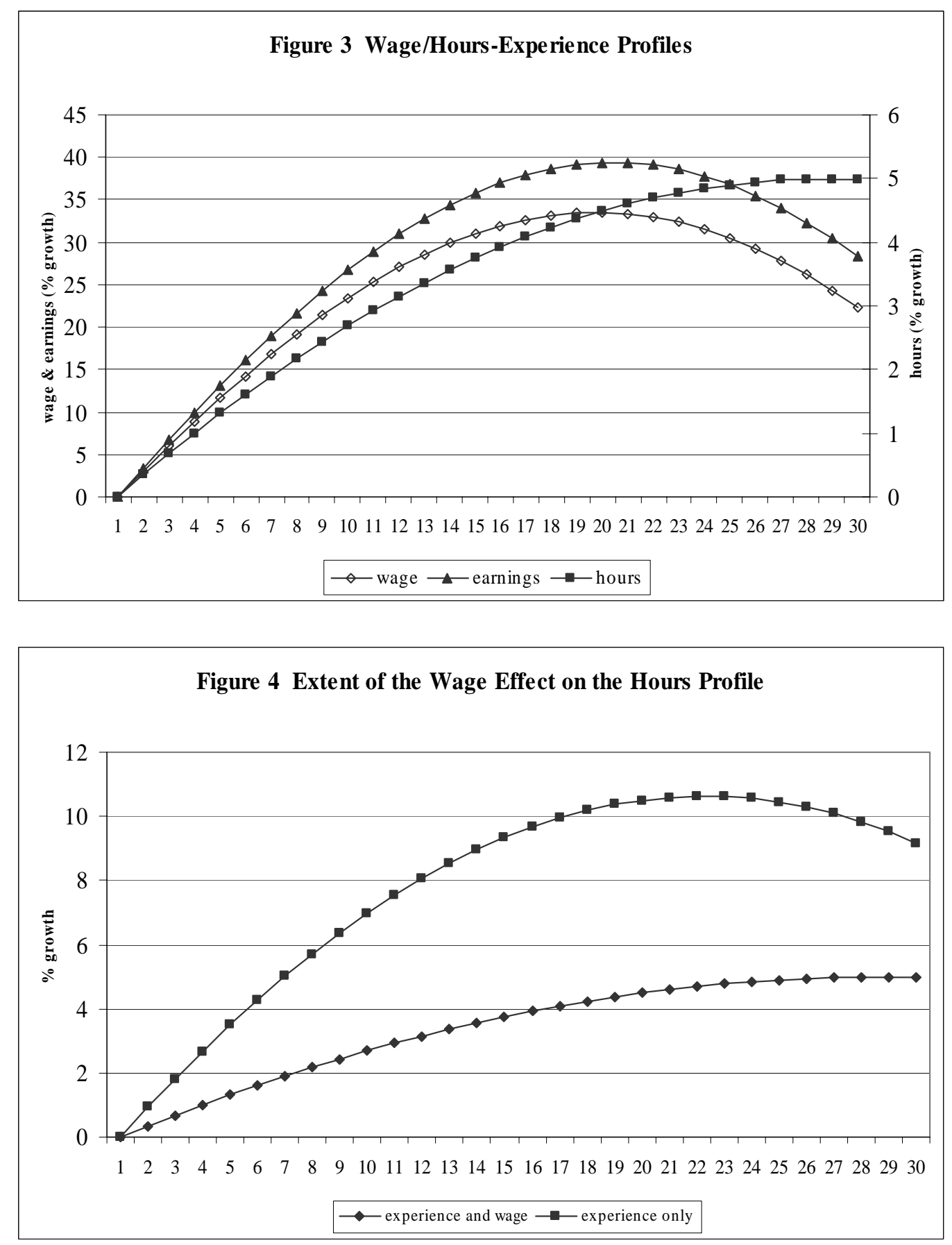

Recall from equation (23) that the hours profile is generated by accounting for a direct positive effect of experience on hours and an indirect negative income (wage) effect. How influential is the latter to the shape of the overall profile? Figure 4 shows the hours profile in respect of the combined experience and wage effects (i.e. 
corresponding to the equivalent profile in Figure (2)) and the profile predicted if there were no wage effect. ${ }^{7}$ Clearly, the wage effect has a substantial influence. As examples, hours growth after 10 years is predicted to be 7 per cent if only experience is accounted for and 2.7 per cent when the wage effect is additionally incorporated while, after 20 years, the respective percentages are 10.5 and 4.5 .

We suggested in Section 3 (e) that sharper evidence in relation to our theoretical predictions may be derived by separating individuals into those with short expected tenure (SET) and long expected tenure (LET). Based on fairly crude heuristics, we defined a SET worker as someone who changed job (at least once) at age 44 or above. Those who changed jobs at an earlier age, or not at all, were defined to be LET workers.

We first predicted in respect of wage rates that returns to experience within the SET group would be expected to be less than within the LET group. Our results in column (ii), Table 2 support this expectation. The shift dummy indicates significantly higher absolute wages for the SET group because this consists, on average, of older workers. $^{8}$ When interacted with the experience variable, however, the SET group displays a significantly lower experience effect on wage growth than its LET equivalent. In the hours' equations (column (iv)), the shift dummy is insignificantly different from zero. As for the effect of experience on hours, the estimates indicate a lower hours' response among SET compared to LET workers. The net experience effect remains positive for the SET group, however. As for as the interacted SET/wage dummy, the income effect is slightly weaker in the SET compared to the

\footnotetext{
${ }^{7}$ That is, simply, the predicted profile after setting $\hat{b}_{3}=0$ in equation (23).

${ }^{8}$ As pointed out by the Reviewer, this explanation is weakened to the extent that our experience variables are capturing age effects. An alternative explanation for the positive coefficient on the shift dummy of the SET group is that members of this group have had more job moves in their careers thereby attaining better-paying job matches.
} 
LET group. We set out the conditions in Section 3 (d) that combine to bring about this outcome.

\section{Concluding remarks}

Investments in general and specific human capital earn an expected rent in the post-investment period. The rent payment to workers has two dimensions. It can be paid in the form of (a) an increment to the wage rate (b) longer per-period hours. We show that, under reasonable conditions, both modes of payment serve to improve contract efficiency in terms of minimising sub-optimal separations in the face of informational asymmetries. Empirical support is obtained from related Mincer equations estimated on data relating to British male workers. Over the working life cycle, the positive effect of rent sharing on hours growth is estimated to be larger than the countervailing negative income effect. This is an important finding in relation to previous empirical literature on hours of work.

There is an obvious empirical extension to this work. Data limitations have prevented us from integrating the role of premium pay into our empirics. Accordingly, our resulting wage earnings growth profiles are lower bounds. Some part of the hours growth due to human capital investments will involve payment of an overtime premium. Elsewhere, we have shown that payment of a premium on marginal per-period hours worked serves as a device that helps to further to reduce sub-optimal separations by the two parties. As and when data sets become available that allow researchers to measure marginal premium rates of pay, along with work experience, then estimates of wage earnings returns to human capital investments may be further refined. 


\section{$\underline{\text { References }}$}

Beaudry, P and J DiNardo (1995), “Is the behavior of hours worked consistent with implicit contract theory?”, Quarterly Journal of Economics, CX, 743-68.

Carmichael, L (1983), "Firm-specific human capital and promotion ladders", Bell Journal of Economics, 14, 251-58.

Ehrenberg, R G (1971), Fringe benefits and overtime behavior, Lexington, Mass.:

Heath

Gustman, A L and T L Steinmeier (1986) A structural retirement model, Econometrica, 54, 555-584.

Hart , R A and Y Ma (2000), "Why do firms pay an 'overtime' premium?", IZA Discussion Paper \# 163.

Hart, R A and R J Ruffell (1993), "The cost of overtime working in British production industries", Economica, 60, 183-201.

Hashimoto, M (1979), "Bonus payments, on-the-job training and lifetime employment in Japan", Journal of Political Economy, 87, 1086-1104.

Hashimoto, M and J Raisian (1985), "Employment, tenure and earnings profiles in Japan and the United States", American Economic Review, 75, 721-35.

Heckman, J (1979), “Sample selection bias as a specification error”, Econometrica, 47, 153-61.

Hübler, O (1989), “Optimal number of job changes”, Zeitschrift für Wirtschaft- und Sozialwissenschaften, 109, 75-92.

Johnson, R W (1996), "The impact of human capital investments on pension benefits", Journal of Labor Economics, 14, 520-54.

Malcomson, J M (1999), "Individual employment contracts", Handbook of Labor

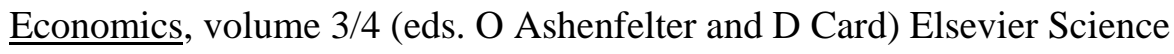
(forthcoming).

Mincer, J (1974), Schooling, experience, and earnings, National Bureau of Economic Research: New York. 
Pencavel, J (1991), Labour markets under trade unionism: employment, wages, and hours, Oxford: Blackwells.

Trejo, S J (1993), “Overtime pay, overtime hours, and labor unions”, Journal of Labor Economics, 11, 253-78. 


\section{Theory Appendix}

(a) Wealth maximisation: first-order conditions

To summarise, we have (where $t_{i}$ means the end of period $i$ ):

$$
\begin{aligned}
& V=V_{1}+V_{2}+V_{3}=V_{1}+V_{2}+V_{f}+V_{q}+V_{s}: \\
& \left.=w_{1} \cdot h_{1}-C\left(M_{2}\right)-D\left(h_{1}\right) \quad \text { (wealth in period } 1\right) \\
& \left.+F_{2} \cdot\left[(1-\delta) \cdot w_{1} \cdot h_{2 f}-C_{f}-D\left(h_{2 f}\right)\right]+w_{3} f \cdot h_{3 f f}-D\left(h_{3 f f}\right) \quad \text { (fired at } t_{1}\right) \\
& +\left(1-F_{2}\right) \cdot Q_{2} \cdot\left\{\left[(1-\delta) \cdot w_{1}+g \cdot M_{2}\right] \cdot h_{2 q}-C_{q}-D\left(h_{2 q}\right)\right. \\
& \left.\left.+\left[\left(w_{1} \cdot(1-\delta)+g \cdot M_{2}\right) \cdot(1-\delta)+M_{3 q}\right] \cdot h_{3 q q}-D\left(h_{3 q q}\right)\right\} \quad \text { (quits at } t_{1}\right) \\
& +\left(1-F_{2}\right) \cdot\left(1-Q_{2}\right) \cdot\left\{\left[(1-\delta) \cdot w_{1}+M_{2}+E\left(\eta_{2} \mid \eta_{2}>\eta_{2} *\right)+E\left(\theta_{2} \mid \theta_{2}>\theta_{2} *\right)\right] \cdot h_{2}-C\left(M_{3}\right)-\right. \\
& \left.D\left(h_{2}\right)\right\} \\
& \text { (stays at } t_{1} \text { ) } \\
& +\left(1-F_{2}\right) \cdot\left(1-Q_{2}\right) \cdot\left\{F_{3} \cdot\left[\left(w_{1} \cdot(1-\delta)+g \cdot M_{2}\right) \cdot(1-\delta) \cdot h_{3 f}-D\left(h_{3 f}\right)\right] \quad \text { (fired at } t_{2}\right) \\
& +\left(1-F_{3}\right) \cdot Q_{3} \cdot\left\{\left[\left(w_{1} \cdot(1-\delta)+g \cdot M_{2}\right) \cdot(1-\delta)+g \cdot M_{3}\right] \cdot h_{3 q^{-}} D\left(h_{3 q}\right)\right\}\left(\text { quits at } t_{2}\right) \\
& +\left(1-F_{3}\right) \cdot\left(1-Q_{3}\right) \cdot\left\{\left[\left(w_{1} \cdot(1-\delta)+M_{2}\right) \cdot(1-\delta)+M_{3}+E\left(\eta_{3} \mid \eta_{3}>\eta_{3} *\right)\right.\right. \\
& \left.\left.\left.\left.+E\left(\theta_{3} \mid \theta_{3}>\theta_{3} *\right)\right] \cdot h_{3}-D\left(h_{3}\right)\right\}\right\} \quad \text { (stays at } t_{2}\right)
\end{aligned}
$$

where $w_{1}, w_{3 f}, h_{1}, h_{2 f}, h_{2 q}, h_{3 f}, h_{3 f f}, h_{3 q}$ and $M_{3 q}$ are exogenously determined constants.

To simplify the notation, let

$$
\begin{aligned}
& \varphi=w_{1} \cdot h_{1}-D\left(h_{1}\right) \\
& \alpha=(1-\delta) \cdot w_{1} \cdot h_{2 f}-C_{f}-D\left(h_{2 f}\right)+w_{3 f} \cdot h_{3 f f}-D\left(h_{3 f f}\right) \\
& \beta=(1-\delta) \cdot w_{1} \cdot h_{2 q}-C_{q}-D\left(h_{2 q}\right)+\left[(1-\delta)^{2} \cdot w_{1}+M_{3 q}\right] \cdot h_{3 q q}-D\left(h_{3 q q}\right) \\
& \gamma=h_{2 q}+(1-\delta) \cdot h_{3 q q} \\
& \tau=(1-\delta)^{2} \cdot w_{1} \cdot h_{3 f}-D\left(h_{3 f}\right)
\end{aligned}
$$




$$
\begin{aligned}
& \mu=w_{1} \cdot(1-\delta)^{2} \cdot h_{3 q^{-}} D\left(h_{3 q}\right) \\
& B=\left[\left(w_{1} \cdot(1-\delta)+M_{2}\right) \cdot(1-\delta)+M_{3}\right] \cdot h_{3}-D\left(h_{3}\right) \\
& A=\left[(1-\delta) \cdot w_{1}+M_{2}\right] \cdot h_{2}-C\left(M_{3}\right)-D\left(h_{2}\right)+F_{3} \cdot\left[\tau+g \cdot M_{2} \cdot(1-\delta) \cdot h_{3 f}\right] \\
& +\left(1-F_{3}\right) \cdot Q_{3} \cdot\left[\mu+g \cdot M_{2} \cdot(1-\delta) \cdot h_{3 q}+g \cdot M_{3} \cdot h_{3 q}\right] \\
& +\left(1-F_{3}\right) \cdot\left(1-Q_{3}\right) \cdot\left\{B+\left[E\left(\eta_{3} \mid \eta_{3}>\eta_{3} *\right)+E\left(\theta_{3} \mid \theta_{3}>\theta_{3} *\right)\right] \cdot h_{3}\right\}
\end{aligned}
$$

where $\varphi, \alpha, \beta, \gamma, \tau$, and $\mu$ are constants.

The first order conditions satisfying max V are $\partial V / \partial \theta_{i}^{*}=\partial V / \partial \eta_{i}^{*}=0(i=2,3)$ :

$$
\begin{aligned}
& \begin{array}{l}
\partial / \partial / \eta_{2} *=f\left(\eta_{2} *\right) \cdot\left\{\alpha-Q_{2} \cdot\left[\beta+\gamma \cdot g \cdot M_{2}\right]-\left(1-Q_{2}\right) \cdot\left[A+h_{2} \cdot E\left(\theta_{2} \mid \theta_{2}>\theta_{2} *\right)\right]\right. \\
\left.\quad-\left(1-Q_{2}\right) \cdot h_{2} \cdot \eta_{2} *\right\}=0
\end{array} \\
& \partial V / \partial / \theta_{2} *=\left(1-F_{2}\right) \cdot q\left(\theta_{2} *\right) \cdot\left\{\left[\beta+\gamma \cdot g \cdot M_{2}\right]-\left[A+h_{2} \cdot E\left(\eta_{2} \mid \eta_{2}>\eta_{2} *\right)\right]-h_{2} \cdot \theta_{2} *\right\}=0 \\
& \text { and }
\end{aligned}
$$

$$
\begin{gathered}
\partial V / \partial / \eta_{3}^{*}=f\left(\eta_{2}^{*}\right) \cdot\left\{\left[\tau+g \cdot M_{2} \cdot(1-\delta) \cdot h_{3 f}\right]-Q_{3} \cdot\left[\mu+g \cdot M_{2} \cdot(1-\delta) \cdot h_{3 q}+g \cdot M_{3} \cdot h_{3 q}\right]\right. \\
\left.-\left(1-Q_{3}\right) \cdot\left[B+h_{2} \cdot E\left(\theta_{2} \mid \theta_{2}>\theta_{2} *\right)\right]-\left(1-Q_{3}\right) \cdot h_{3} \cdot \eta_{3} *\right\}=0 \\
\partial V / \partial / \theta_{3}^{*}=\left(1-F_{3}\right) \cdot q\left(\theta_{3} *\right) \cdot\left\{\left[\mu+g \cdot M_{2} \cdot(1-\delta) \cdot h_{3 q}+g \cdot M_{3} \cdot h_{3 q}\right]\right. \\
\left.-\left[B+h_{3} \cdot E\left(\eta_{3} \mid \eta_{3}>\eta_{3}{ }^{*}\right)\right]-h_{3} \cdot \theta_{3} *\right\}=0
\end{gathered}
$$

(b) Period 2 wage-hour contract

The optimal period 2 wage-hour contract is obtained as follows. If the firm decides to fire a worker at the end of period 1 , then

$$
(1-\delta) \cdot w_{1}+M_{2}+\eta_{2}<w_{2}
$$

or

$$
\eta_{2}<\eta_{2}^{*}=w_{2}-(1-\delta) \cdot w_{1}-M_{2}
$$


Substituting (A7) into f.o.c. (A3) gives (10).

On the other hand, the worker will quit at the end of period 1 if

$$
\begin{aligned}
h_{2} \cdot w_{2}+ & h_{2} \cdot \theta_{2}-D\left(h_{2}\right)-C\left(M_{3}\right)+V_{S}<\left\{\left[(1-\delta) \cdot w_{1}+g \cdot M_{2}\right] \cdot h_{2 q}-C_{q}-D\left(h_{2 q}\right)\right. \\
& \left.+\left[\left(w_{1} \cdot(1-\delta)+g \cdot M_{2}\right) \cdot(1-\delta)+M_{3 q}\right] \cdot h_{3 q q}-D\left(h_{3 q q}\right)\right\}
\end{aligned}
$$

The worker is assumed to be forward looking. He therefore considers current returns, $\left[h_{2} \cdot w_{2}+h_{2} \cdot \theta_{2}-D\left(h_{2}\right)-C\left(M_{3}\right)\right]$, as well as future returns, $V_{s}$, if he stays with the firm at period 2 when he makes his decision. The right-hand-side of the above inequality is the sum of the wealth over periods 2 and 3 if the worker quits. Rewrite (A8):

$\theta_{2}<\theta_{2}^{*}=-w_{2}+\left[\beta+\gamma \cdot g \cdot M_{2}+D\left(h_{2}\right)+C\left(M_{3}\right)-V_{S}\right] / h_{2}$

Substituting (A9) into f.o.c. (A4) gives (9) if $M_{2}$ is sufficiently large or $\delta$ is relatively small.

(c) Period 3 wage-hour contract

If the firm decides to fire a worker at the end of period 2, then

$$
(1-\delta)^{2} \cdot w_{1}+M_{2} \cdot(1-\delta)+M_{3}+\eta_{3}<w_{3}
$$

or

$$
\eta_{3}<\eta_{3}^{*}=-\left[(1-\delta)^{2} \cdot w_{1}+M_{2} \cdot(1-\delta)+M_{3}-w_{3}\right]
$$

Substituting (A10) into (A5) gives (16).

On the other hand, the worker will quit at the end of period 2 if

$$
h_{3} \cdot w_{3}+h_{3} \cdot \theta_{3}-D\left(h_{3}\right)<\left[\mu+g \cdot M_{2} \cdot(1-\delta) \cdot h_{3 q}+g \cdot M_{3} \cdot h_{3 q}\right]
$$


or

$$
\theta<\theta^{*}=-w_{3}-\left\{D\left(h_{3}\right)-\left[\mu+g \cdot M_{2 \cdot} \cdot(1-\delta) \cdot h_{3 q}+g \cdot M_{3} \cdot h_{3 q}\right]\right\} / h_{3}
$$

Substituting (A11) into (A6) gives (15).

(d) Human capital investment over the life cycle

The first-order conditions satisfying max $V$ are $\partial V / \partial M_{i}=0(i=2,3)$ are given by

$$
\begin{gathered}
\partial V / \partial M_{2}=-C^{\prime}\left(M_{2}\right)+\left(1-F_{2}\right) \cdot Q_{2} \cdot \gamma \cdot g+\left(1-F_{2}\right) \cdot\left(1-Q_{2}\right) \cdot\left[h_{2}+g \cdot F_{3} \cdot(1-\delta) \cdot h_{3 f}\right. \\
\left.+g \cdot\left(1-F_{3}\right) \cdot Q_{3} \cdot(1-\delta) \cdot h_{3 q}+\left(1-F_{3}\right) \cdot\left(1-Q_{3}\right) \cdot(1-\delta) \cdot h_{3}\right]=0
\end{gathered}
$$

$\partial V / \partial M_{3}=\left(1-F_{2}\right) \cdot\left(1-Q_{2}\right) \cdot\left[-C^{\prime}\left(M_{3}\right)+g \cdot\left(1-F_{3}\right) \cdot Q_{3} \cdot h_{3 q}+\left(1-F_{3}\right) \cdot\left(1-Q_{3}\right) \cdot h_{3}\right]=0$

Equations (A12) and (A13) imply that

$$
\begin{aligned}
C^{\prime}\left(M_{2}\right) & -C^{\prime}\left(M_{3}\right)=\left(1-F_{2}\right) \cdot Q_{2} \cdot \gamma \cdot g+\left(1-F_{2}\right) \cdot\left(1-Q_{2}\right) \cdot\left[h_{2}+g \cdot F_{3} \cdot(1-\delta) \cdot h_{3 f}\right] \\
& -\delta\left(1-F_{2}\right) \cdot\left(1-Q_{2}\right) \cdot\left(1-F_{3}\right) \cdot\left[g \cdot Q_{3} \cdot h_{3 q}+\left(1-Q_{3}\right) \cdot h_{3}\right] \\
& -\left(F_{3}+Q_{3}-F_{3} \cdot Q_{3}\right) \cdot\left(1-F_{3}\right) \cdot\left[g \cdot Q_{3} \cdot(1-\delta) \cdot h_{3 q}+\left(1-Q_{3}\right) \cdot(1-\delta) \cdot h_{3}\right]>0
\end{aligned}
$$

if $F_{i}, Q_{i}(i=2,3)$ and $\delta$ are small. Therefore, we have

$$
M_{2}>M_{3}>0
$$




\section{Data Appendix}

Variable definitions in respect of the results shown in Table 2 are as follows. (In addition, regressions include year dummies.)

\begin{tabular}{|c|c|}
\hline Variable & Definition \\
\hline Wage & straight-time hourly wage rate (see footnote 5) \\
\hline Hours & individual's total weekly paid-for hours \\
\hline Exp & age of individual minus age when completed full-time education \\
\hline Partner & $\begin{array}{l}0=\text { married or living together } 1=\text { single, widowed, divorced, } \\
\text { separated }\end{array}$ \\
\hline chil 0 & no dependent children under 19 \\
\hline chil $1 *$ & youngest dependent child is between 0 and 3 ( 0 and 4 ) \\
\hline chil 2 & youngest dependent child is between 5 and 11 (4 and 11) \\
\hline chil 3 & youngest dependent child is between 12 and 18 \\
\hline size $0 *$ & 1 - 24 employees at workplace \\
\hline size 1 & 25 - 49 employees at workplace \\
\hline size 2 & 50 or more employees at workplace \\
\hline ind 1 & Agriculture, forestry \& fishing \\
\hline ind 2 & Energy \& water supplies \\
\hline ind $3^{*}$ & Mineral extraction metals \& chemicals \\
\hline ind 4 & Metal goods, engineering \& vehicles \\
\hline ind 5 & Other manufacturing \\
\hline ind 6 & Construction \\
\hline ind 7 & Distribution, hotels \& catering \\
\hline ind 8 & Transport \& communication \\
\hline ind 9 & Banking, finance, insurance, business services \& leasing \\
\hline ind 10 & Other services \\
\hline
\end{tabular}

Note: * indicates the omitted variable in regression analyses. 